\title{
EXPERIÊNCIA DA DOR PARA FAMILIARES DE CRIANÇAS COM DOENÇA FALCIFORME
}

\author{
JÉSSICA DA SILVA CRUZ1; SILVIA DA SILVA SANTOS PASSOS²; ALINE SILVA \\ GOMES XAVIER ${ }^{3}$; FERNANDA DA SILVA PASSOS ${ }^{4}$ \\ ${ }^{1}$ Bolsista PROBIC/UEFS, Graduanda do Curso de Enfermagem da Universidade Estadual de Feira de Santana, email: \\ jel_cruz@hotmail.com \\ ${ }^{2}$ Orientadora, Departamento de Saúde da Universidade Estadual de Feira de Santana, email: ssspassos@yahoo.com.br \\ ${ }^{3}$ Coordenadora do Projeto IKINI - Práticas de cuidado à pessoa com doença falciforme e sua família, Departamento de Saúde \\ da Universidade Estadual de Feira de Santana, email: asgx80@gmail.com \\ ${ }^{4}$ Participante do Núcleo Interdisciplinar de Estudos sobre Desigualdades em Saúde, Departamento de Saúde da Universidade \\ Estadual de Feira de Santana, email: psilvananda@gmail.com
}

PALAVRAS CHAVE: dor; doença crônica; criança.

\section{INTRODUÇÃO}

A dor na Doença Falciforme (DF) é o resultado da obstrução da microcirculação causada pelo afoiçamento das hemácias, sendo considerada a manifestação mais dramática do quadro da doença (LOBO; MARRA; SILVA, 2007). Nas crianças a dor é a primeira manifestação da doença e inicia-se nos pés e mãos sendo denominada de dactilite ou síndrome mão-pé (BRASIL, 2006). Dias e outros (2013) identificaram que as consequências da dor na vida infantil exercem importante impacto na vida cotidiana, incluindo o lazer, a vida escolar, o crescimento e o desenvolvimento (SILVA; BELLATO; ARAÚJO, 2013). Segundo Silva, Bellato e Araújo (2013), a DF provoca um grande impacto sobre a vida da família, especialmente quando se trata de crianças. Sendo assim, o objeto desse estudo é a "a experiência do familiar que vivencia a dor na criança com DF", onde buscaremos responder a seguinte questão de pesquisa: como é a experiência do familiar que vivencia a criança sentindo dor secundária a DF? O objetivo geral é "Compreender a experiência da família que vivencia as crises dolorosas secundárias a DF na criança" e o objetivo específico "Conhecer as estratégias de enfrentamento utilizadas pelos cuidadores familiares no momento das crises álgicas decorrentes da DF na criança". Esse estudo se justifica devido a abordagem escassa de estudos sobre a temática. Estudos dessa natureza podem contribuir para o aperfeiçoamento sobre a temática com vistas a orientar os familiares a identificarem precocemente as manifestações de dor, assim como as estratégias utilizadas para seu enfrentamento, culminando com a redução do sofrimento. Além de que a identificação precoce possibilitará aos envolvidos no cuidado à criança a adotarem medidas preventivas de agravamento da dor.

\section{MATERIAL E MÉTODO}

Estudo descritivo, exploratório com abordagem qualitativa. O projeto foi aprovado pelo Comitê de Ética em Pesquisa com seres humanos da Universidade Estadual de Feira de Santana, sob $\mathrm{n}^{\mathrm{o}}$ 1.440.239. Realizado no Centro de Referência para as Pessoas com Doença Falciforme do município de Feira de Santana, no período de março a abril de 2017. Participaram do estudo sete familiares de crianças com DF e que integram e frequentam o Centro de Referência para as Pessoas com Doença Falciforme. Para a coleta de dados foi empregado um roteiro semiestruturado, as entrevistas foram gravadas e posteriormente transcritas, observando os princípios éticos da pesquisa, onde foram adotadas as recomendações do Conselho Nacional de Pesquisa (CONEP) conforme preconiza a Resolução 466/12 do Conselho Nacional de Saúde (BRASIL, 2012, p.59). Os dados foram analisados utilizando-se a Análise de conteúdo temática proposta por Bardin (2011). 


\section{RESULTADOS E DISCUSSÃO}

Os resultados desse estudo mostraram que a experiência do cuidado à criança com crises álgicas secundárias a DF é realizado geralmente pelas mães e que, a maioria delas, não sabe quantificar quantas vezes já experienciou essas crises dolorosas em seu filho com DF, por serem inúmeras essas vezes. Assim, após análise das falas dos participantes, obtivemos três categorias temáticas: "Vivenciando o sofrimento e a impotência diante da dor do filho com DF"; "Estratégias para o enfrentamento da dor na criança" e; "A não realização de atividades habituais pela criança".

$\mathrm{Na}$ primeira categoria podemos perceber nos relatos que os cuidadores estão despreparados para o momento em que a criança apresenta as crises álgicas, sentindo-se impotentes, pois não sabem ao certo quais atitudes devem tomar para aliviar a sintomatologia da criança adoecida.

"[...] É muito difícil à gente tá ao lado de uma pessoa sua que tá com uma dor crônica, dor intensa, sofrendo, e você impossibilitado de fazer nada, a não ser tá dando uma assistenciazinha ali, de água ou de medicamento, somente isso.” (F-01)

"[...] Porque você ver seu filho assim, se contorcendo de dor, chorando e você não poder fazer nada, é muito difícil." (F-03)

Com isso, acompanhar o sofrimento dos filhos é, para as famílias, uma situação geradora de angústia, dor e ansiedade. Estudos mostram que os procedimentos dolorosos são momentos difíceis e de completa impotência para as famílias, já que nada podem fazer para aliviar o sofrimento do filho (MOREIRA; ANGELO, 2008).

$\mathrm{O}$ familiar que presta outros cuidados à criança com DF sente que não podem fazer nada no momento da dor do filho, mesmo estando ao lado dele, isso aumenta os sentimentos negativos da experiência vivenciada. Sendo assim, com o intuito de aliviar a dor da criança, esses familiares recorrem, na maioria das vezes, aos hospitais.

“[...] Eu dava o dipirona, mas não conseguia passar, eu tive que trazer ela pro Hospital da Criança.” (F-05)

“[...] Eu fiquei sabendo que ela sentiu dor, eu tive que internar ela, foi péssimo.” (F06)

"Porque são dores que eu não tenho como resolver, são dores que no hospital que dá medicação correta. Tem as medicações correta." (F-07)

Quando as famílias reconhecem a piora do quadro clínico da criança, devido a não obtenção dos efeitos esperados dos cuidados prestados no domicílio, procuram auxílio profissional (AMARAL et al., 2012). Há uma tendência ao uso domiciliar de medicamentos para alívio dessa dor, seguido de hospitalização, conforme a orientação médica e também do Ministério da Saúde (BRASIL, 2009).

Vemos que a primeira alternativa a ser utilizada pelos cuidadores para alívio das crises álgicas nas crianças são os analgésicos de uso domiciliar que são utilizados como paliativos até que a criança seja encaminhada até um hospital, para aplicação de um analgésico mais potente. Esses familiares utilizam também estratégias não farmacológicas, como o uso de compressas quentes e massagens, como forma de amenizar as dores.

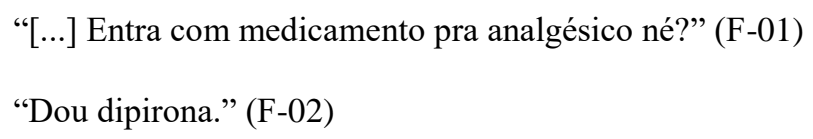

“Eu, primeiramente, entro logo com o medicamento em casa né?” (F-03) 
“[...] Aí eu faço sempre uma massagem, as vezes esquento uma água, faço uma compressa com água morna.” (F-03)

"Faço massagem na perna dela, vou dando massagem, boto compressa de água quente." (F-06)

Tostes e outros (2008) afirmam que quanto ao manejo da dor na DF, muitos dos episódios dolorosos podem ser controlados em domicílio, utilizando-se analgésicos via oral ou outras condutas não farmacológicas, dependendo da intensidade da dor da criança (RODRIGUES; ARAÚJO; MELO, 2010).

Porém, os cuidadores relatam que esse processo doloroso interfere nas atividades diárias da criança, eles percebem que a criança se recusa a realizar atividades típicas da idade, como brincar e ir à escola. Nas falas a seguir podemos ver que as crianças deixam de realizar as atividades de lazer por conta da dor.

\begin{abstract}
“Ele não joga muita bola, ele não anda muito de bicicleta...” (F-04)
"Ela não brincava, com essa dor ela não brincava, só ficava no colo, só chorando." (F-06)
\end{abstract}

"Deixou de ir pra escola né, de tá envolvida em atividades que é da idade né..." (F01)

“[...] Na escola mesmo ele deixa muito a desejar na escola assim sabe? Porque sempre quando ele sente crise ele passa no hospital uns 5,6,10,15 dias dependendo da situação dele, aí fica muito favorável a escola também. Falta na escola.” (F-02)

Alvim e outros (2009) trazem que apesar de variada gravidade clínica da DF, um contingente significativo de pacientes sofre as consequências de uma doença crônica e grave, exacerbada por crises que lhes acrescentam sofrimento, dor intensa e hospitalizações, agravando suas dificuldades escolares e trazendo-lhes marcantes limitações no lazer e no prazer.

\title{
CONSIDERAÇÕES FINAIS
}

Nesse estudo, percebemos que o familiar que possui o filho adoecido por DF experiencia sentimentos como impotência e desespero, pois sentem-se despreparados para agir no momento das crises álgicas. Assim, os familiares utilizam as estratégias domiciliares que conhecem para amenizar as dores, como o uso de analgésicos, de compressas quentes e massagens, até se dirigirem ao hospital. Além disso, as frequentes internações por períodos prolongados fazem com que as crianças tenham prejuízos escolares e no lazer, pois as crianças deixam de brincar por medo de desencadear as crises de dor ou pelas crises já em curso. Com isso, informações sobre a DF deve ir além das unidades de saúde e dos familiares, deve abranger também as escolas, pois esse ambiente deve estar ciente das causas das faltas escolares das crianças adoecidas, procurando estratégias para minimizar o prejuízo educacional e social na infância. Assim como, o acompanhamento das famílias e a educação em saúde são as melhores estratégias para prevenir ou amenizar as complicações da DF, principalmente nas crises de dor, proporcionando, melhor qualidade de vida para os envolvidos nesse processo.

\section{REFERÊNCIAS}


ALVIM, R._C. et al. Perfil e impacto da dor em crianças e adolescentes com doença

falciforme. Minas Gerais, 2009. Disponível em: <http://www.nupad.medicina.ufmg.br/wpcontent/uploads/2016/12/Perfil_e_impacto_da_dor.pdf>. Acesso em: 20 jun. 2017.

AMARAL, R. F. C., et al. Itinerário terapêutico no cuidado mãe-filho: interfaces entre a cultura e biomedicina. Rev. RENE, v. 13, n. 1, p. 85-93. 2012. Disponível em:

<http://www.revistarene.ufc.br/revista/index.php/revista/article/view/20/16>. Acesso em: 04 abr. 2017.

BRASIL. Ministério da Saúde. Secretaria de Atenção à Saúde. Departamento de Atenção Especializada. Manual de condutas básicas na doença falciforme. Brasília: Editora do Ministério da Saúde, 2006. Disponível em:

$<$ http://www.riocomsaude.rj.gov.br/Publico/MostrarArquivo.aspx?C=Y0\%2BU19IsUXc\%3D >. Acesso em: 04 abr. 2017.

Ministério da Saúde. Conselho Nacional de Saúde. Resolução no 466, de 12 de dezembro de 2012. Diretrizes e normas regulamentadoras de pesquisas envolvendo seres humanos. Disponível em:

<http://bvsms.saude.gov.br/bvs/saudelegis/cns/2013/res0466_12_12_2012.html>. Acesso em: 04 abr. 2017.

Ministério da Saúde, Departamento de Atenção Especializada. Manual de eventos agudos em doença falciforme. Brasília, DF: Editora do Ministério da Saúde, 2009.

Disponível em:

<http://bvsms.saude.gov.br/bvs/publicacoes/manual_eventos_agudos_doenca_falciforme.pdf> . Acesso em: 04 abr. 2017.

BARDIN, Laurence. Análise de conteúdo. São Paulo: Edições 70, 2011. 229 p.

DIAS, T. L., et al. A dor no cotidiano de cuidadores e crianças com anemia falciforme.

Psicologia USP, v. 24, n. 3, p. 391-411, 2013. Disponível em:

<http://www.scielo.br/pdf/pusp/v24n3/a03v24n3.pdf >. Acesso em: 04 abr. 2017.

MOREIRA, PL; ANGELO, M. Tornar-se mãe de criança com câncer: construindo a parentalidade. Rev. Latino Americana Enferm., v. 16, n. 3, p. 355-361, 2008. Disponível em: <http://www.scielo.br/pdf/rlae/v16n3/pt_04.pdf>. Acesso em: 20 mai. 2017.

RODRIGUES, C. C. M.; ARAÚJO, I. E. M.; MELO, L. L. A família da criança com doença falciforme e a equipe enfermagem: revisão crítica. Rev. Bras. Hematol. Hemoter., v. 32, n. 3, p. 257-264. São Paulo, 2010. Disponível em: <http://www.scielo.br/pdf/rbhh/v32n3/aop79010.pdf>. Acesso em: 08 jun. 2017. SILVA, A. H.; BELLATO, R.; ARAÚJO, L. F. S. Cotidiano da família que experiência a condição crônica por anemia falciforme. Rev. Eletr. Enf., v. 15, n. 2, p. 437-446, 2013. Disponível em: <https://www.fen.ufg.br/fen_revista/v15/n2/pdf/v15n2a17.pdf >. Acesso em: 08 mai. 2017.

TOSTES, M. A. et al. Avaliação de dor em crianças e adolescentes portadores de doença falciforme. Rev. Ciênc. Méd., v. 17, n. 3-6, p.141-147, 2008. Disponível em:

$<$ http://periodicos.puccampinas.edu.br/seer/index.php/cienciasmedicas/article/view/751/731>. Acesso em: 22 mai. 2017. 